\title{
Neonicotinoids, bees and opportunity costs for conservation
}

\author{
by Walters, K.F.A.
}

Copyright, Publisher and Additional Information: This is the author accepted manuscript. The final published version (version of record) is available online via Wiley

Please refer to any applicable terms of use of the publisher.

DOI: http://dx.doi.org/10.1111/icad.12177

Harper Adams

University

Walters, K.F.A. 2016. Neonicotinoids, bees and opportunity costs for conservation. Insect Conservation and Diversity, 9 (5), pp. 375-383. 


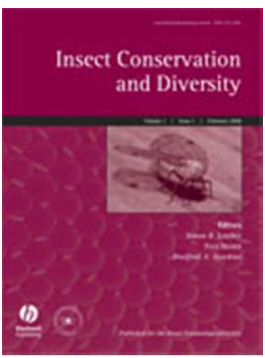

\section{Neonicotinoids, bees and opportunity costs for conservation}

\begin{tabular}{|r|l|}
\hline Journal: & Insect Conservation and Diversity \\
\hline Manuscript ID & ICDIV-16-0008.R1 \\
\hline Manuscript Type: & Forum \& Policy \\
\hline Date Submitted by the Author: & n/a \\
\hline Complete List of Authors: & Walters, Keith; Harper Adams University, Crop Sciences \\
\hline Keywords: & $\begin{array}{l}\text { Neonicotinoids, Neonicotinoid insecticides, EU Moratorium, IPM, } \\
\text { Sustainable pest management, Ecosystem services, Conservation }\end{array}$ \\
\hline
\end{tabular}


Tel: 07552689357

Email: kwalters@harper-adams.ac.uk

Running title: Neonicotinoids, bees and conservation costs

9 Abstract

1. Restrictions on the use of neonicotinoid insecticides in the European Union are widely debated in relation to bee decline, but their potential consequences at the interface between sustainable crop production and conservation are less frequently discussed.

2. This paper raises issues to be considered if we are to achieve a balanced consensus in this contentious area.

3. The common legal framework governing testing and environmental impact for all chemical crop protection products is highlighted, leading to concerns that the current focus on impact of neonicotinoids is diverting attention from other drivers of bee decline to the detriment of a balanced conservation strategy.

4. The evidence for the causal relationship between neonicotinoid use and bee decline is considered and information gaps requiring further work identified.

5. How research into the parallel use of pesticides and beneficial invertebrates in integrated pest management (IPM) can inform the pollinator debate is highlighted. The importance of the neonicotinoids in major IPM systems is illustrated, leading to discussion of potential consequences for conservation of biodiversity and sustainable crop protection if they were lost and we revert to reliance on other pest management tools.

6. Increasing agricultural production and conservation are sometimes viewed as being contradictory and the paper concludes by calling for a broadening of the debate to consider the complimentary objectives of bee conservation and sustainable crop production, so that advances in both fields can hasten consensus on the way forward, rather than perpetuating the current rather polarised debate. 
In a note to the 1884 edition of Old Mortality, Robert Louis Stevenson observes that "sooner or later everybody sits down to a banquet of consequences", a relevant warning when we consider the wider impacts of the current debate on the effect of neonicotinoid insecticides on pollinators.

The decline of bee species during the last 60 years has been attributed to various stressors including habitat loss, loss of floral diversity in key landscapes, predators, parasites, disease and pesticides (Goulson et al., 2015; Vanbergen et al., 2013; Ollerton et al., 2014). A key driver of public and environmental concern relating to bee decline has centred around the loss of the ecosystem services they provide, principally crop pollination, and conservation issues. It is, however, often not recognised that although wild bees contribute significantly to production of insect pollinated crops, this service delivery is limited to a small subset of known bee species (Kleijn et al., 2015). As these do not include many threatened species, the exposure to insecticides of those at-risk species is severely

45 limited. The importance of diversity, however, in providing resilience through species redundancy or complementarity should be recognised (Brittain et al., 2013; Hoehn et al., 2008; Rader et al., 2012, 2013). Although bee decline has been more fully documented in Europe and North America, it is likely that common global drivers might be expected to produce similar outcomes in other continents (Carvalheiro et al., 2013; Koh et al., 2015). The decline in Europe commenced long before the introduction of neonicotinoids (Bonmarco et al., 2011; Carvalheiro et al., 2013) and they have been subject to and met the same registration requirements as all other pesticides currently used in

52 EU crop production. Despite these observations, neonicotinoid insecticides have become a focus of

53 attention as a potential driver of the decline (Blacquiere, 2012; Godfray et al., 2014; Goulson, 2013).

54 This led in 2013 to the European Union announcing a restriction on the use as seed treatments of

55 three active ingredients (Imidacloprid, Thiamethoxam and Clothianidin) in bee attractive crops (EC, 56 2013), which is now commonly referred to as a moratorium. 


\section{Registration testing and conservation}

59 To obtain registration for use in the EU, candidate active ingredients/products are subject to

60 harmonised registration requirements (EC, 2009a) that can only be met after environmental hazard

61 and safety has been established by extensive laboratory and field research. This work has to be

62 generated under Good Laboratory Practice (GLP) or other stringent auditable quality standards, and

63 conform to detailed guidelines originally established by independent experts (EPPO, 2010; OECD,

64 2013). The data are assessed by independent specialist scientists at national registration authorities,

65 and use (subject to legally enforceable label restrictions) is allowed only after multiple criteria have

66 been satisfied, including acceptably low risk of environmental damage. Unfortunately, such data are

67 rarely published due to commercial considerations, thus this large body of evidence is not available

68 or discussed by academics or environmental interest groups. This may have contributed to an

69 imbalanced debate, with the strong focus on perceived impacts of a single class of insecticides

70 drawing attention away from other key (perhaps more dominant) drivers of bee decline such as

71 landscape change reducing floral resources and nest sites for bees, pests and disease (Vanbergen et

72 al, 2013). Critically this has also detracted from research into, and development of, agricultural

73 techniques that mitigate pesticide effects (Matthews et al., 2014). If such mitigation factors have

74 significant effects on resultant risk then conservation efforts will not be well served by a narrow

75 focus on neonicotinoids that draws attention away from achievable goals of improving landscapes to

76 enhance botanical biodiversity.

78 Given the common legal framework enforces equally high environmental standards for all chemical

79 crop protection products, why are the neonicotinoids so prominent in the debate when many

80 authors suggest that other stressors (particularly landscape change/habitat) are more dominant 
81 drivers of pollinator decline (Vanbergen et al, 2013)? Many other questions arise but key issues

82 include:

83 Is the evidence regarding hazards and risks posed by neonicotinoids conclusive?

84 Is the moratorium, which in the UK is leading to use of older (arguably more hazardous) chemistries

85 (Nicholls, 2015), itself inadvertently raising serious concerns for conservation of biodiversity and

86 sustainable crop production?

87

89 Such issues are of global, not just European importance as many countries are considering their

90 future policy on neonicotinoid use.

\section{Evidence and information gaps}

93 If there is clear evidence that neonicotinoid insecticides on their own constitute a major factor in

94 bee declines, then irrespective of the relative importance of other drivers the EU moratorium would

95 be justified on conservation grounds.

96

97 The use of the products as seed treatments leading to pollinator exposure through translocation into

98 nectar and pollen has received most attention in the current debate. Very low levels of the three

99 active ingredients subject to the moratorium have been reported in pollen and nectar in treated

100 commercial fields (EFSA 2013a, b, c), and some of these records undoubtedly result from improved

101 analytical technology that has reduced detection limits (Walters, 2013). Exposure to low levels of

102 these active ingredients does not necessarily result in significant risk as the dose delivered is often

103 too low to stimulate either acute or chronic lethal or sub-lethal responses (Carreck \& Ratnieks, 
104 2014). This partly explains why predicted risks surrounding their use have not been confirmed in

105 most field investigations (Cutler et al., 2014; Godfray et al., 2015; Rundlof et al., 2015).

Another aspect of use of treated seed has, however, led to some well reported large scale incidents

Worryingly, significant gaps in datasets used to defend the decision to introduce the moratorium have now been recognised. The research conducted has a narrow focus; most studies have investigated Imidacloprid (>70\% laboratory studies and $>85 \%$ field studies), but this active ingredient 
130 had to large extent been superseded in Europe as a seed treatment for relevant crops prior to the

131 introduction of the moratorium (Walters, 2013). Reliable extrapolation of the effects reported for

132 imidacloprid to other neonicotinoids is prevented by variable characteristics of the active ingredients

133 (Blacquiere et al., 2012; Godfray et al., 2014). For example, unlike thiamethoxam and clothianidin,

134 imidacloprid displays wide variation in acute oral toxicity of (4-400 ng/bee). It also has several toxic

135 plant metabolites in the pollen and nectar, differing again from thiamethoxam and clothianidin. In

136 addition microsomal mono-oxygenase P450 enzymes do not appear as a major route of metabolism

137 in bees, whereas P450 enzymes feature strongly in the metabolism of thiamethoxam and

138 clothianidin, potentially reducing impact on bees (Thompson et al, 2014a). These differences, and

139 others, underline the importance of considering such active ingredients individually to maximise our

140 understanding of their impact on conservation issues

141

142 Additional gaps in the evidence-base presented in support of the moratorium are also evident; most

143 studies investigate Apis species with few on other pollinators (including wild bees) despite the

144 greater importance of wild pollinators as providers of ecosystem services (Blacquiere et al., 2012;

145 Garibaldi et al., 2013; Godfray et al., 2014). This is important as there is growing evidence for

146 variable responses to neonicotinoid exposure between bee taxa (Rundlof et al., 2015; Piiroinen \&

147 Goulson, 2016). For example, differential sensitivity of honeybees and bumblebees to a dietary

148 insecticide (imidacloprid) have been reported, whereby following exposure bumblebees

149 progressively developed a dose-dependent reduction in feeding rate, whereas honeybees did not

150 (Cresswell, 2012). Further, the EFSA collations of data on neonicotinoid contamination of nectar and

151 pollen under commercial field conditions demonstrate that bees showing effects in many laboratory

152 experiments have been exposed to unrealistically high levels of pesticides when three key dosage

153 characteristics (concentration, duration and choice) are taken into account (Carreck \& Ratnieks,

154 2014). Complications in replicating field exposure are also magnified by the range of application

155 technology used by farmers, which target insecticides at pests whilst reducing the exposure of non- 
target organisms (Matthews et al., 2014). This is a key but rarely discussed consideration if we are to

157 simultaneously meet our essential conservation and sustainable food production targets.

Legislation governing pesticide use has also been strengthened to reduce environmental risk, coupled with operator training (a legal requirement in the UK aimed at maintaining both environmental and operator safety), that compliment these technological advances (EC 2009b;

Matthews et al., 2014). Such rules governing pesticide use have not, however, been considered when interpreting the findings of many studies of pesticide impacts on pollinators. This exacerbates conditions, and drawing clear conclusions on conservation risk and mitigation.

A sub-set of these problems, particularly usage characteristics and dose rates, have beset field and semi-field studies, possibly explaining very different responses reported following exposure to neonicotinoids in commercial crops, with some authors recording no impact at either individual or colony levels whilst others note detrimental effects (Cutler \& Scott-Dupree, 2014; Cutler et al., 2014; Gill, R. J., et al., 2012; Rundlöf et al., 2015). For example, high dose rates of two pesticides (a neonicotinoid and a pyrethroid) were used in a study investigating the effect of these active ingredients individually and in combination (Gill et al., 2012). In this case the imidacloprid dose rate was nearly an order of magnitude greater than the highest residue reported in nectar in any European commercial crop (data on commercial field residues from EFSA, 2012). The correct full label rate dilution for the pyrethroid spray was used but the volume applied per unit area resulted in a greater than permitted (in the EU) dose rate, resulting in over-exposure. A second example is provided by a study of effects of clothianidin applied to spring oilseed rape (Rundlöf et al., 2015). In this case the residues in pollen and nectar were again an order of magnitude higher than reported in any commercial fields in the EU, or in any previous field studies of this active ingredient (e.g. Cutler \& Scott-Dupree, 2014). Although such investigations provide evidence of responses at very high 
182 exposure rates it is difficult to determine their significance within the more typical range

183 encountered in commercial fields. Thus, if the outcomes are to be used in support of conservation

184 decision making, it is essential that such studies be repeated at realistic exposure rates or scenarios.

\section{5}

The difficulties of reaching an overall consensus on future neonicotinoid use are also exacerbated by

the challenge of publishing studies showing no-effects in high impact factor journals, which prevents

the full range of evidence being placed in the public arena. If balanced conclusions on hazards posed

are to be arrived at, editors should counter the bias towards publishing results showing positive

effects which can lead to a misleading overview of real-environment responses due to promotion of data generated using supra-field exposure rates.

These problems with the evidence base, coupled with a failure to publish data generated for registration portfolios, may partly explain why an increasing number of studies appear to challenge the original decision to register the neonicotinoids for use. This is worrying as failure to accurately characterise and quantify hazards and risks posed by this class of insecticides, may give the appearance that the moratorium will have greater impact in halting bee decline than might ultimately occur. This would impede rather than support conservation efforts by diverting attention away from other critical drivers such as landscape change which require urgent and immediate research and action. Thus further well targeted, well designed and conclusive research is needed to fill the above data gaps. In addition, monitoring over time is required to understand the full consequences of either use or a ban on the use of neonicotinoids. Only then can the relative importance of neonicotinoid insecticides and other drivers be assessed and conservation responses properly reflect this balance. Failure to do so may result in our addressing the wrong problems. Currently, monitoring of the impact on crop production of the EU neonicotinoid ban in the UK is in its early stages and requires further time before clear conclusions emerge (Dewar \& Walters, 2016). 
208 There is growing concern that the resultant loss of neonicotinoids following the EU ban, and the

209 consequential increased reliance on alternative pest management products may lead to increased

210 rather than decreased environmental impacts on non-target organisms. If it does, it could impede

211 efforts to develop sustainable pest management practices. Is this the case and what can be learnt

212 from the extensive research relating to integrated pest management (IPM) that could inform this

213 debate?

214

215

Perspectives from Integrated Pest Management

216

217 With the approaching review of the EU moratorium Raine \& Gill (2015) correctly concluded that we

218 must balance the risks of neonicotinoid exposure for insect pollinators and the value these

219 pesticides provide to ensure crop yield and quality; does it matter if we lose these products?

220

221 As illustrated by the lack of publications, the highly focussed debate and large literature on the

222 impact of this class of crop protection products on pollinators has hitherto not been matched by

223 similar debate on their wider importance in crop production. The wide scale use of neonicotinoid

224 pesticides in all major and many minor crops worldwide, and their importance in resistance

225 management, illustrates their central role in agricultural production (Blacquiere et al., 2012;

226 Goulson, 2013). It is therefore worrying that the relative environmental impact of possible

227 alternative pest management products is rarely raised. Whereas occasional calls for us to evaluate

228 alternative options for pest control (including IPM) have been made (Goulson et al., 2015), current

229 use and importance of neonicotinoids in such systems is rarely highlighted (Budge et al., 2015; North

230 et al., 2016). Further, the wider value of information on their impact on or compatibility with natural

231 enemies is almost never considered when assessing impact on pollinators. With an increasing global

232 population sustainable crop production is a priority concern which should complement not compete

233 with conservation objectives, so what can be learnt from IPM research? 
235 Transferable Biology: Narrow interpretation of outcomes of pollinator research can in some cases be

236 avoided by considering information generated by IPM research. A recent study by Kessler et al

237 (2015) investigating the proposal that bumblebees could detect and avoid neonicotinoid treated

238 crops, came to the apparently contradictory conclusions that for imidacloprid and thiamethoxam

239 they could not detect the active ingredient, consumed less contaminated nectar, but none-the-less

240 foraged preferentially on treated nectar. In this case, irrespective of whether the bees consumed

241 treated nectar preferentially, long established natural enemy research has shown that detection of a

242 pesticide is not always necessary for reduction of predator exposure to treated food (Singh, 2001;

243 Singh et al., 2004; Thornham et al., 2007). For example in well controlled laboratory experiments

244 Coccinella septempunctata consumed fewer pesticide resistant aphids that had been pre-treated

245 with active ingredients from other pesticide groups than untreated aphids, but choice tests indicated

246 that they were unable to detect the low residue (approximately $19 \mathrm{~nL}$ ) deposited on the aphid

247 cuticle (Thornham et al., 2007). It was concluded that physiological processes resulted in the

248 observed temporary reduction in feeding rate while metabolic detoxification takes place thus

249 protecting the biological control agent. This response has been used to facilitate IPM strategies

250 when insecticides and C. septempunctata are used simultaneously. This is potentially important for

251 interpretation of the bumblebee study (Kessler et al., 2015), as a similar reversible reduction in

252 consumption of imidacloprid and thiamethoxam treated nectar substitute to those noted for

253 Coccinellids had been demonstrated previously in bumblebees, using bioassays that generated no

254 evidence of behavioural avoidance (Thompson et al., 2014b). Thus reference to the Coccinellid study

255 may suggest a partial explanation of some of Kessler et al. findings without the need to invoke

256 behavioural attraction or avoidance. Such work conducted on natural enemies for IPM can

257 strategically inform work on pollinators in relation to responses to neonicotinoid (and other)

258 insecticides. Similar improved integration of findings of IPM and pollinator research may support the 
259 avoidance of narrow interpretation, reducing the risk of misleading or incomplete information being 260 used as a basis for conservation policy.

261

Compatibility with natural enemies and IPM: Research into IPM is, however, more central to the debate over the impacts of this insecticide class on pollinators and our mitigation strategy, than the simple provision of transferable biology. A little discussed consideration is the many reports of compatibility of neonicotinoid active ingredients with a wide range of biological control agents. Many studies have been conducted on the lethal and sub-lethal effects of a wide range of natural enemies or bio-control agents, from a broad range of taxonomic groups, which consider impact on both individual species and the natural enemy complexes that occur on crops (e.g. Cuthbertson et al. 2012; Roubos et al., 2014a; Shah et al. 2007; Smith \& Krischik 1999; Vincent et al. 2000). The findings of these studies record widespread compatibility with non-target beneficial organisms at field realistic exposure rates, as is the case for many insecticides that have passed through current registration processes. As a result the neonicotinoids have been found to be both suitable for, and frequently are used as components of commercial IPM systems. The environmental impact of such compounds can also be further reduced by application methods that target the pest more closely, and availability in both spray and seed treatment formulations offers IPM specialists more options to reduce exposure of non-target organisms (Matthews, 2014), including pollinators. This should be taken into account when balancing conservation and crop production decision making. doses, application method, spatial and temporal targeting of applications, selection of formulation and creation of refugia, amongst many others (Oakley et al., 1996; Roubos et al. 2014b). At the 
285 landscape scale, habitat quality and composition affect the magnitude of ecological services

286 available, and also mitigate against the effects of pesticides on natural enemies. Current research is

287 establishing the relative importance of local and landscape effects of pesticides on natural enemies

288 and other ecosystem service provision to support government policy development and development

289 of improved land management strategies (e.g. Kennedy et al. 2013; Roubos et al. 2014b). This work

290 is yielding information of potential value to the pollinator debate.

291

292 IPM is context sensitive and locally adapted; to tailor such dynamic systems to local needs requires

293 the availability of a range of insecticide products/classes to facilitate their use, and neonicotinoids

294 often feature. The loss of a significant sub-set of this class of insecticides may thus impair the

295 development of sustainable pest control approaches at the time when they have never been more

296 important in crop production.

297

298 Such concerns would, of course, be lessened if key sustainable pest control systems for the major

299 crops that rely on this class of insecticides did not currently exist. There are, however, multiple

300 examples of key control systems that utilise these products. The concept of integrated control has

301 been applied in Arizona (Naranjo and Ellsworth 2009); for example for more than 15 years Bemisia

302 tabaci has been controlled on cotton using a strategy based on neonicotinoid insecticides. This has

303 resulted in an estimated 70\% reduction in foliar insecticide use, promoting both

304 conservation/enhanced utilization of ecosystem services, with a saving to the industry of $>\$ 200$

305 million (encouraging uptake). The system simultaneously promotes conservation of biodiversity and

306 sustainable crop production and is thought to be so important that cross commodity guidelines for

307 managing the use of the insecticide class are now in place to sustain efficacy (Palumbo et al. 2003).

308

309 This is by no means the only example of the use of neonicotinoids in sustainable management

310 systems. Control strategies aimed at temperate climate fruit crops in Michigan have been effective 
311 against aphids, leafhoppers, and true fruit flies (depending on active ingredient) and have driven

312 grower transition from broad spectrum insecticides to reduced-risk classes. Neonicotinoids are key

313 to sustainable strategies for cotton in Australia (fundamental to successful IPM especially for control

314 of secondary sucking pests such as mirids and Aphis gossypii, where emergence of neonicotinoid

315 resistance resulted in substantial efforts to recover efficacy). Products based on this class of

316 insecticides are central to sustainable pest management in cotton in India, grapes in Tunisia, invasive

317 pests transported on world trade in plants and plant products, and many others (Chen et al. 2013;

318 Cuthbertson et al., 2012; Daane et al., Herron \& Wilson 2011; Mansour et al. 2010). Loss of

319 neonicotinoids where no reduced-risk alternatives (tested for environmental hazard and registered

320 for major commodities) are available will undermine continued use of such sustainable systems,

321 progressive development of new ones, the ecosystem services they rely on, and drive the continued

322 use of more broad-spectrum products. Such an eventuality would be to the detriment of efforts to

323 conserve biodiversity in the agricultural landscape. We must consider that sustainable crop

324 production and conservation of biodiversity should be complementary and not competitive, and

325 management and conservation strategies must both be developed to reflect this principle if we are

326 to make progress in solving the complex issues that we face.

327

328 Disruption of sustainable crop protection: This is not a theoretical problem but one that we already

329 begin to encounter. Concerns are already being raised regarding the disruption of existing pest

330 management strategies following the EU moratorium (e.g. Bird, 2015; Pucci, 2015), due to both loss

331 of effective pest control and potential detrimental impact on natural enemy populations that exert

332 incidental background pest suppression.

334 Nicholls (2013) reviewed the implications of the restriction of use of the neonicotinoids

335 imidacloprid, clothianidin and thiamethoxam on crop protection in oilseeds and cereals in the UK. 
336 Prior to the moratorium on their use UK crop production specialists recommended a single

337 neonicotinoid seed treatment to control damage caused each year on oilseed rape by both cabbage

338 stem flea beetle (CSFB; Psylliodes chrysocephala), and aphid vectors of turnip yellows virus (Myzus

339 persicae). Both species display pyrethroid resistance, and aphids are resistant to pirimicarb, the

340 alternative registered active substances available for use. Consequently in the first two years after

341 the moratorium was introduced many crops have received multiple sprays of older (potentially more

342 environmentally hazardous) products. Despite such multiple treatments, CSFB incidence in key

343 oilseed growing areas has significantly increased leading to substantial establishment failure

344 (Nicholls, 2015; Pucci, 2015, Walters \& Dewar, 2016).For example, initial figures have shown that 5\%

345 of the national crop sown in 2014 was lost during the establishment phase due to CSFB damage,

$3461.5 \%$ was replanted but 3.5\% was abandoned (Nicholls, 2015). To this will be added any losses

347 accrued from the impact of the aphid borne viruses transmitted in autumn (HGCA, 2013). Such

348 losses vary between years dependent on a range of factors, important amongst which are aphid

349 population size and weather at the time the crop is susceptible to infection. Yield depressions of up

350 to $30 \%$ occur and result in farmers using insecticides to reduce transmission rates. The loss of

351 neonicotinoid seed treatments has resulted in farmers now having to rely on more intensive use of

352 older products despite the associated resistance problems noted above (HGCA, 2013).

There are also concerns that the current situation in UK oilseed rape might present challenges to our ongoing efforts to conserve the wild pollinator populations we are attempting to protect?

Discussions in the farming press indicate that the increase in crop failure described above, an

357 expectation that significant yield losses have resulted from reduced pest control, and worries about

358 the resistance status and environmental effects of alternatives to neonicotinoid seed treatments,

359 may lead to a reduction in the OSR acreage sown in the UK and elsewhere. Although Kleijn et al.

360 (2015) suggest that many at-risk pollinator species do not appear frequently in mass flowering crops, 
361 such crops have been shown to be beneficial to bees such as non-Bombus generalist pollinators

362 (Riedinger et al., 2015) thus loss of a proportion of the already restricted forage in the farming

363 landscape may exacerbate conservation challenges.

The impact of the moratorium on the use of these products or, as some start to call for, its'

broadening to encompass other neonicotinoid insecticides, must also be considered against the ongoing trend of increasing loss of available plant protection products. The report of The Anderson

Centre on "The effect of the loss of plant protection products on UK agriculture and horticulture and the wider economy" identifies three main policies that they conclude threaten their availability in Europe/the UK (The Anderson Centre 2014). These include the approval process leading to pesticide registration at EU level, the implementation of the Water Framework Directive at national level which will influence/restrict the use of pesticide products, and restrictions on neonicotinoid seed treatments. They identify 87 of the current approximately 250 active substances as being threatened but suggest this is probably an underestimate. Of these, $59 \%$ of insecticides were classified as being at high risk of loss, and $41 \%$ as medium; none were low risk (The Anderson Centre 2014). As environmentally sustainable crop management requires the availability of a range of modes of action, then serious consideration must be given to this report when scientific advice is provided to policy makers reviewing the moratorium. A reversion to a narrow range of older chemistries is likely to risk the emergence of wider challenges and threats to both the natural environment and conservation efforts, particularly in agroecosystems. This problem is significantly under-represented in discussions and planning of the conservation of biodiversity and as a result may lead to serious unintended consequences if it emerges as a threat to worldwide food security through yield reductions. Under such circumstances it might, for example, lead to pressure for increasing the proportion of land devoted to agriculture to the detriment of natural environments. 


\section{6 \\ Broadening the debate; risks and consequences}

387 In conclusion, UN estimates that to keep pace with growing demand there needs to be a $70 \%$

388 increase in global food production by 2050 are widely reported (Godfray, 2010). The agricultural

389 industry currently, therefore, faces a complex of contradictory challenges. Production targets need

390 to be increased but this is made more difficult by the limited availability of land. The problem is

391 exacerbated by the essential need to devote large areas of suitable land for conservation of

392 biodiversity. In addition the impact of climate change (e.g. energy crops competing for land), a

393 decreasing number of pesticides leading to frequent resistance problems (and associated damage to

394 some ecosystem services), and financial constraints on production research (Godfray, 2010) add to

395 the issues. To achieve the overall aim without causing unacceptable environmental damage requires

396 sustainable intensification without making the mistakes of the 1960s (when application of crop

397 protection products that have since been superseded, using approaches that have been changed

398 and improved, resulted in significant non-target impact). Thus the targets have to be achieved in

399 conjunction with associated (complimentary) conservation and biodiversity objectives. These

400 challenges can be met within the important constraints imposed by conservation principles and

401 objectives, but sustainable combined strategies will require a broad focus and balanced judgements

402 based (in some cases) on more robust scientific evidence, that take account of a wide range of

403 factors. Against a background of issues illustrated above, however, conservation outcomes are

404 currently not well served by a too narrow focus on a single class of insecticides, particularly as they

405 are widely considered not to be the principle driver of bee decline (Vanbergen et al., 2013).

406 Broadening of the debate to consider the complimentary objectives of bee conservation and

407 sustainable crop production would therefore enable advances in both fields to be more readily used

408 to hasten consensus on the way forward, surely preferable to our current polarised debate that

409 reduces the prospect of such consensus being achieved.

410 
411 If the narrowly focused European debate regarding the future of the neonicotinoids is not

412 broadened to recognise the limitations of the current evidence base, take account of the full range

413 of impinging issues, and adopt a balanced overview of the consequences accruing from the loss of a

414 substantial proportion of a class of modern insecticides, then it will only add to the problems we

415 face. If the evidence ultimately indicates that the risks identified outweigh the advantages of their

416 use then the way forward is clear, but Raine and Gill (2015) are correct, we must "find the right

417 balance between the risks of neonicotinoid exposure for insect pollinators and the value these

418 pesticides provide to ensure crop yield and quality". Otherwise we may be at risk of making

419 decisions which have far reaching impacts without taking a sufficiently holistic overview. Let us heed

420 the warning of Robert Louis Stevenson.

421

422

423

References

Bird, J. (2015) EU Farmers blame 11\% oilseed yield drop on neonic ban. Agrow, www.agra-

425

net.com/agra/agrow/markets-regulatory/Europe/EU-farmers-blame-11-oilseed-yield-drop-on-

426

neonic-ban--1.htm

427

428

Blacquiere, T., Smagghe, G., van Gestel, C.A.M. \& Mommaerts, V. (2012) Neonicotinoids in bees: a

429

review on concentrations, side effects and risk assessment. Ecotoxicology, 21, 973-992.

430

431

Bonmarco, R., O. Lundin, H. G. Smith, and M. Rundlöf. (2011) Drastic historic shifts in bumble-bee

432 community composition in Sweden. Proceedings of the Royal Society B: Biological Sciences 279, 309-

433315.

434 
435 Brittain C., Kremen C., Klein A.-M. (2013) Biodiversity buffers pollination from changes in

436 environmental conditions. Global Change Biology, 19, 540-547

437

438 Budge, G.E., Garthwaite, D., Crowe, A., Boatman, N.D., Delaplane, K.S., Brown, M.A., Thygesen, H.H.

439 \& Piretravalle, S. (2015) Evidence for pollinator cost and farming benefits of neonicotinoid seed

440 coatings on oilseed rape. Scientific Reports 5, 12574DOI:10.1038/srep12574

441

442 Carreck, N.L \& Ratnieks, F.L.W. (2014) The dose makes the poison: have "field realistic" rates of

443 exposure of bees to neonicotinoid insecticides been overestimated in laboratory studies? Journal of

444 Apicultural Research, 53, 607-614.

445

446 Carvalheiro L.G., Kunin W.E., Keil P., Aguirre-Gutiérrez J., Ellis W.N., Fox R., Groom Q., Hennekens S., 447 Van Landuyt W.,Maes D., van de Meutter F., Michez D, Rasmont P., Ode B., Potts S.G., Reemer M., 448 Roberts S.P., Schaminée J., WallisDeVries M.F., \& Biesmeijer J.C (2013) Species richness declines and 449 biotic homogenisation have slowed down for NW-European pollinators and plants. Ecological Letters $450 \quad 16(7) 870-878$.

451

452 Chen, Y., Vanlerberghe-Masutti, F., Wilson, L.J., Barchia, I., McLoon, M.O., Smith, T. \& Herron, G.A.

453 (2013) Evidence of superclones in Australian cotton aphid Aphis gossypii Glover (Aphididae:

454 Hemiptera). Pest Management Science, 69, 938-948.

455

456 Cresswell, J.E., Page, C.J., Uygun, M.B., Holmbergh, M., Li, Y., Wheeler, J.G., Laycock, I., Pook, Ibarra,

457 N.H. de., Smirnoff, N. \& Tyler, C.R. (2012) Differential sensitivity of honey bees and bumblebees to a

458 dietary insecticide (imidacloprid). Zoology 115, 365-371.

459 
460 Cuthbertson, A.G.S., Mathers, J.J., Croft, P., Nattriss, N., Blackburn, L.F., Luo, W., Northing, P., Muari, 461 T., Jacobson, R.J. \& Walters, K.F.A. (2012) Prey consumption rates and compatibility with pesticides 462 of four predatory mites from the family Phytoseiidae attacking Thrips palmi Karny (Thysanoptera: 463 Thripidae). Pest Management Science, 68, 1289-1295.

464

465

Cutler, G.C. \& Scott-Dupree, S.D. (2014) A field study examining the effects of exposure to 466 neonicotinoid seed-treated corn on commercial bumble bee colonies Ecotoxicology, 23, 1755-1763.

467

468

Cutler, G.C., Scott-Dupree, C.D., Sultan, M., McFarlane, A.D. \& Brewer, L. (2014) A large-scale field 469 study examining effects of exposure to clothianidin seed-treated canola on

honey bee colony health, development, and overwintering success. PeerJ 2, e652

471

https://dx.doi.org/10.7717/peerj.652

472

473

Dewar, A.M. \& Walters, K.F.A. (2016) BCPC Pests and Beneficials Group Inaugural Review Meeting 474 Can we continue to grow oilseed rape? A report of the recent meeting on oilseed rape pest control 475 at NIAB Park Farm, Cambridge, UK. (in press).

EC (2009a) EC 1107/2009 Regulation (EC) No 1107/2009 of the European Parliament and of the

478 Council of 21 October 2009 concerning the placing of plant protection products on the market and

479 repealing Council Directives $\underline{79 / 117 / E E C}$ and $\underline{91 / 414 / E E C}$.

480

481 EC (2009b) DIRECTIVE 2009/128/EC of the European Parliament and of the Council of 21 October

4822009 establishing a framework for Community action to achieve the sustainable use of pesticides.

483 Official Journal of the European Union, 309/71-86.

484 
485 EC (2013) Commission implementing regulation (EU) No 485/2013 of 24 May 2013 amending

486 Implementing Regulation (EU) No 540/2011, as regards the conditions of approval of the active

487 substances clothianidin, thiamethoxam and imidacloprid, and prohibiting the use and sale of seeds

488 treated with plant protection products containing those active substances. Official Journal of the

489 European Union, 139/12-26.

490

491

EFSA (2013a) Conclusion on the peer review of the pesticide risk assessment for bees for the active

492

substance imidacloprid. EFSA Journal 11(1), 3068, 55pp.

493

494

EFSA (2013b) Conclusion on the peer review of the pesticide risk assessment for bees for the active

495

substance clothianidin. EFSA Journal 11 (1): 3066, 58pp.

496

497

EFSA (2013c) Conclusion on the peer review of the pesticide risk assessment for bees for the active

498

substance thiamethoxam. EFSA Journal 11 (1): 3067, 68pp.

499

500

501

Ellsworth, P.C., Palumbo, J.C., Naranjo, S.E., Dennehy, T.J. \& Nichols, R.L. (2006) Whitefly

Management in Arizona Cotton 2006. [Online]. IPM Series 18, Publ. No. AZ1404, University of

502

Arizona, College of Agriculture and Life Sciences, Cooperative Extension, Tucson, AZ, 4 pp. Available:

503 http://cals.arizona.edu/pubs/insects/ az1404.pdf [accessed: 26 June 2016].

504

505

EPPO (2010) Environmental risk assessment scheme for plant protection products; Honeybees.

506 OEPP/EPPO Bulletin, 40, 323-331.

507

508 EU (2010) Commission Directive 2010/21/EU of 12 March 2010 amending Annex 1 to Council

509 Directive 91/414/EEC as regards the specific provisions relating to clothianidin, thiamethoxam,

510 Fipronil and Imidacloprid. Official Journal of the European Union, L65/27 
512 Forster, R. (2012) Risk mitigation measures for seed treatments using neonicotinoids. Proceedings

$51311^{\text {th }}$ International Symposium of the IC-PBR Bee Protection Group, Wageningen (The Netherlands),

514 November 2-4, 2011. Julius-Kühn-Archive 437, 63-68. http://dx.doi.org/10.5073/ika.2012.437.013

515

516 Garibaldi, L.A., Steffan-Dewenter, I., Winfree, R., Aizen, M.A. et al. (2013) Wild pollinators enhance

517 fruit set of crops regardless of honey bee abundance. Science, 33, 1608-1611.

518

519

Gill, R. J., Ramos-Rodriguez, O. \& Raine, N. E. (2012) Combined pesticide exposure severely affects

520

individual- and colony-level traits in bees. Nature, 491, 105-108.

521

522

Godfray, H.C.J., Beddington, J.R., Crute, I.R., Haddad, L., Lawrence, D., Muir, J.F., Pretty, J., Robinson,

S., Thomas, S.M. \& Toulmin, C. (2010) Food security: The challenge of feeding 9 Billion People.

Science, 327 (5967), 812-818.

525

526

527

Godfray, H.C.J., Blacquière, T., Field, L.M., Hails, R.S., Petrokofsky, G., Potts, S.G., Raine, N.E., Vanbergen, A.J. \& McLean, A.R. (2014) A restatement of the natural science evidence base concerning neonicotinoid insecticides and insect pollinators. Proceedings Royal Society B 281,

529 http://dx.doi.org/10.1098/rspb.2014.0558

530

531 Godfray, H.C.J., Blacquière, T., Field, L.M., Hails, R.S., Potts, S.G., Raine, N.E., Vanbergen, A.J. \&

532 McLean, A.R. (2015) A restatement of recent advances in the natural science evidence base

533 cocerning neonicotinoid insecticides and insect pollinators. Proceedings Royal Society B 282,

534 http://dx.doi.org/10.1098/rspb.2015.1821

535 
536 Goulson, D. (2013) An overview of the environmental risks posed by neonicotinoid insecticides.

537 Journal of Applied Ecology, 50, 977-987.

538

539 Goulson, D., Nicholls, E., Botías, C. \& Rotheray, E.L. (2015) Bee declines driven by combined stress

540 from parasites, pesticides, and lack of flowers. ScienceExpress

541 http://dx.doi.org/10.1126/Science.1255957

542

543 Herron, G.A. \& Wilson, L.J. (2011) Neonicotinoid resistance in Aphis gossypii Glover (Aphididae:

544 Hemiptera) from Australian cotton. Australian Journal of Entomology, 50, 93-98.

545

546 HGCA (2013) Will aphid borne virus problems increase? HGCA Hand Out No. 6.

547 www.cereals.ahdb.org.uk/hgca/cereals 2013/handouts/ho6.pdf

548

549 Hoehn P., Tscharntke T., Tyianakis J.M., \& Steffan-Dewenter I. (2008) Functional group diversity of

550 bee pollinators increases crop yield. Proceedings of the Royal Society - B-Biological Sciences, 275,

$551 \quad 2283-2291$

552

553 IPBES, 2016 IPBES (2016): Summary for policymakers of the assessment report of the

554 Intergovernmental Science-Policy Platform on Biodiversity and Ecosystem Services on pollinators,

555 pollination and food production. S.G. Potts, V. L. Imperatriz-Fonseca, H. T. Ngo, J. C. Biesmeijer, T. D.

556 Breeze, L. V. Dicks, L. A. Garibaldi, R. Hill, J. Settele, A. J. Vanbergen, M. A. Aizen, S. A. Cunningham,

557 C. Eardley, B. M. Freitas, N. Gallai, P. G. Kevan, A. Kovács-Hostyánszki, P. K. Kwapong, J. Li, X. Li, D. J.

558 Martins, G. Nates-Parra, J. S. Pettis, R. Rader, and B. F. Viana (eds.). IPBES, Bonn, Germany pp. 1-28.

559 Kennedy, C.M., Lonsdorf, E., Neel, M.C., et al. (2013) A global quantitative synthesis of local and

560 landscape effects on wild bee pollinators in agroecosystems. Ecology Letters, 16, 584-599

561 
562 Kessler, S.C., Tiedeken, E.J., Simcock, K.L., Derveau, S., Mitchell, J., Softley, S., Stout, J.C., Wright, G.A.

563 (2015) Bees prefer foods containing neonicotinoid pesticides. Nature,

564 http://dx.doi.org/10.1038/nature14414 (2015)

565

566 Kleijn, D., Winfree, R., Bartomeus, I., Carvalheiro, L.G. et al. (2015) Delivery of crop pollination

567 services is an insufficient argument for wild pollinator conservation. Nature Communications, DOI:

$568 \quad 10.1038 /$ ncomms8414

569

570

Mansour, R., Youssfi, F.E., Lebdi, K.G. \& Rezgui, S. (2010) Imidacloprid applied through drip irrigation

571

as a new promising alternative to control mealybugs in Tunisian vineyards. Journal of Plant

572

Protection Research, 50, 314-319.

573

574

575

Matthews, G., Bateman, R. \& Miller, P. (2014) Pesticide Application Methods, 4th Edition. Wiley-

576

577
Naranjo, S.E. \& Ellsworth, P.C. (2009) Fifty years of the integrated control concept: moving the model and implementation forward in Arizona. Pest Management Science, 65, 1267-1286.

Nicholls, C. (2013) Implications of the restriction on the neonicotinoids: imidacloprid, clothianidin and thiamethoxam on crop protection in oilseeds and cereals in the UK. HGCA Research Review No. 77. www.cereals.ahdb.org.uk

Nicholls, C. (2015) Assessing the impact of the restrictions on the use of neonicotinoid seed treatments. www.hgca.com/media/632560/Neonicotinoids-planting-survey-report 
587 North, J.H., Gore, J., Catchot, A.L., Stewart, S.D., Lorenz, G.M., Musser, F.R., Cook, D.R., Kerns, D.L. \&

588 Dodds, D.M. (2016) Value of neonicotinoid insecticide seed treatments in mid-south soybean

589 (glycine max) production systems. Journal of Economic Entomology doi10.1093/jee/tow035

590

591 Oakley, J.N., Walters, K.F.A., Ellis, S.A., Green, D.B., Watling, M. \& Young, J.E.B. (1996) Development

592 of selective aphicide treatments for integrated control of summer aphids in winter wheat. Annals of

593 Applied Biology, 128, 423-436.

594

595

OECD (2013) OECD Guidelines for the testing of chemicals, Section 2 Effects on biotic systems.

596 www.oecd-ilibrary.org/environment/oecd-guidelines-for-the-testing-of-chemicals-section-2-effects-

597 on-biotic-systems 20745761

598

599 Ollerton J., Erenler H., Edwards M., \& Crockett R. (2014) Extinctions of aculeate pollinators in Britain

600 and the role of large scale agricultural changes. Sciences 346, 1360-1362.

601

602 Palumbo J.C., Ellsworth P.C., Dennehy T.J. \& Nichols R.L. (2003) Cross commodity guidelines for

603 neonicotinoid insecticides in Arizona. [Online]. IPM Series 17, Publ. No. AZ1319, University of Arizona,

604 College of Agriculture and Life Sciences, Cooperative Extension, Tucson, AZ, 4 pp. Available:

605 http://cals.arizona.edu/pubs/insects/az1319.pdf [accessed: 26 June 2016]

606

607 Piiroinen, S. \& Goulson, D. (2016) Chronic neonicotinoid pesticide exposure and parasite stress

608 differentially affects learningin honeybees and bumblebees. Proceedings of The Royal Society $B$

60920160246.

610

611 Pucci, J (2015) EU Farmers feel first hit of neonicotinoid ban. Farm Chemicals International.

612 November 2015, 12-15. 
614 Rader R., Howlett B.G., Cunningham, S. A., Westcott, D.A. \& Edwards, W. (2012) Spatial and

615 temporal variation in pollinator effectiveness: do unmanaged insects provide consistent pollination

616 services to mass flowering crops? Journal of Applied Ecology 49, 126-134.

617

618

Rader R., Reilly J., Bartomeus I., \& Winfree, R. (2013) Native bees buffer the negative impact of

619

climate warming on honey bee pollination of watermelon crops. Global Change Biology 19, 3103-

620

3110.

621

622

623

Raine, N. \& Gill, R.J. (2015) Ecology: Tasteless pesticides affect bees in the field Nature, http://dx. doi:10.1038/nature14391

624

625

626

627 $1351-1360$.

628

629

Roubos, C.R., Rodriguez-Saona, C., Holdcraft, R., Mason, K.S. \& Isaacs, R. (2014a) Relative toxicity and

630 residual activity of insecticides used in blueberry pest management: Mortality of natural enemies.

631 Journal of Economic Entomology, 107, 277-285.

632

633 Roubos, C.R., Rodriguez-Saona, C. \& Isaacs, R. (2014b) Mitigating the effects of insecticides on

634 arthropod biological control at field and landscape scales. Biological Control - Special Issue on

635 Impact of Environmental Change on Biological Control, 75, 28-38.

636

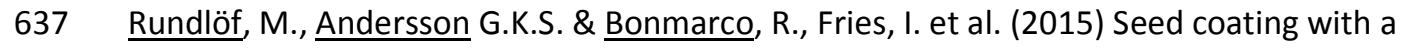

638 neonicotinoid insecticide negatively affects wild bees. Nature, 521, 77-80. 
640 Shah, F.A., Ansari, M.A., Prasad, M. \& Butt, T.M. (2007) Evaluation of black vine weevil (Otiorhynchus

641 sulcatus) control strategies using Metarhizium anisopliae with sublethal doses of insecticides in

642 disparate horticultural growing media. Biological Control, 40, 246-252.

643

644 Singh, R.R. (2001). The behaviour of the ladybird, Coccinella septempunctata, in response to sub-

645 lethal doses of insecticide. PhD Thesis, University of Newcastle-upon-Tyne, UK.

646

647 Singh, SR; Walters, KFA; Port, GR; Northing, P (2004). Consumption rates and predatory activity of

648 adult and fourth instar larvae of the seven spot ladybird Coccinella septempunctata (L.), following

649 contact with dimethoate residues and contaminated prey in laboratory arenas. Biological Control 30,

$650 \quad 127-133$.

651

652 Smith, S.F. \& Krischik, V.A. (1999) Effects of Systemic Imidacloprid on Coleomegilla maculata

653 (Coleoptera: Coccinellidae). Environmental Entomology, 28, 1189-1195.

654

655 The Anderson Centre (2014). The effect of the loss of plant protection products on UK agriculture

656 and horticulture and the wider economy. www.nfuonline.com/andersons-final-report/

657

658 Thompson, H.M., Fryday, S.L., Harkin, S. \& Milner, S. (2014a) Potential impact of synergism in

659 honeybees (Apis mellifera) of exposure to neonicotinoids and sprayed fungicides in crops.

660 Apidologie, 45, 545-553.

661

662 Thompson, H.M., Wilkins, S., Harkin, S., Milner, S. \& Walters, K.F.A. (2014b) Neonicotinoids and 663 bumble bees (Bombus terrestris): Effects on nectar consumption in individual workers. Pest 664 Management Science, DOI: 10.1002/ps.3868 
665

666 Thornham, D.G., Stamp, C., Walters, K.F.A., Mathers, J.J., Wakefield, M., Blackwell, A. \& Evans, K.A.

667 (2007) Feeding responses of adult seven-spotted ladybirds, Coccinella septempunctata (Coleoptera, 668 Coccinellidae), to insecticide contaminated prey in laboratory arenas. Biocontrol Science and 669 Technology, 17, 983-994.

670

671 Vanbergen, A.J. and The Insect Pollinators Initiative (2013) Threats to an ecosystem service:

672 pressures on pollinators. Frontiers in Ecology and the Environment,

673 http://dx.doi.org/10.1890/120126

674

675 Vincent, C., Ferran, A., Guige, L., Gambier, J. \& Brun, J. (2000) Effects of imidacloprid on Harmonia

676 axyridis (Coleoptera: Coccinellidae) larval biology and locomotory behaviour. European Journal of

677 Entomology, 97, 501-506.

678

679 Walters K.F.A (2013). Data, data everywhere but we don't know what to think? Neonicotinoid

680 insecticides and pollinators. Outlooks Pest Management, 24, 151-155. 